\title{
AN I.B.M. 1620 COMPUTER PROGRAM TO FIT FREQUENCY DISTRIBUTIONS
}

\author{
By A. Kozak ${ }^{1}$ and D. D. Munro²
}

The importance of recognizing frequency distributions likely to be encountered in forest sampling has been suggested (Smith and Ker, 1957). With a knowledge of probability distributions, proper transformations, mathematical models, and statistical analyses can be used. In many instances, such as sequential sampling and analyses of variance, the distribution of the observed values must be known before the analysis can be successfully completed. Anyone who has tried to determine the theoretical distribution which best fits a set of observed values will appreciate what a time-consuming task this can be.

When the senior author became interested in developing a sequential sampling scheme for Douglas fir cone and seed insects (Kozak, 1962), it was decided to write a computer program to fit observed sets of data to the four probability distributions commonly recognized in forest sampling: the normal, Poisson, binomial and negative binomial.

This note briefly outlines the program written by the authors in FORTRAN II (McCracken and Daniel, 1961) for the I.B.M. 1620 Electronic Computer at the University of British Columbia Computing Centre.

Parameters of the data are calculated: the mean, standard deviation, number of frequency classes, the value $\mathrm{P}$ for the binomial distribution and the constants $\mathrm{K}$ and $\mathrm{P}_{1}$ for the negative binomial distribution. The expected frequencies for each class are calculated for each distribution using the appropriate mathematical formulae (Bliss and Owen, 1958; Brunk, 1960; Steel and Torrie, 1960). To test the goodness of fit of the observed and expected frequencies, individual chi-square values are calculated for each frequency class and total chi-square values for each distribution. Degrees of freedom are also tabulated. The program will accept a maximum of 20 frequency classes, but this may be increased up to the capacity of the computer memory.

Compiling, complete with listing the program, requires 11.7 minutes. To complete one analysis, that is, to calculate all parameters, fit four distributions and calculate chi-square values requires approximately 2.4 minutes.

The availability of this program has facilitated the preparation of the sequential sampling plan mentioned above. It is hoped that in the future it will also prove helpful in analysing other forest data and will enable foresters or statisticians to select the best statistical techniques for comprehensive and valid analyses.

A limited number of copies of the program can be made available to interested persons.

Literature Cited

BLISS, C. I. and A. R. G. OWEN. 1958. Negative binomial distribution with a common K. Biometrika 45(2) 37-58.

BRUNK, H. D. 1960. An introduction to Mathematical Statistics. Ginn and Company, New York.

${ }^{1}$ Research assistant and graduate student, Faculty of Forestry, U.B.C.

${ }^{2}$ Lecturer, Faculty of Forestry, U.B.C. 
KOZAK, A. 1962. Sequential Sampling of Megastigmus Spermotrophus (Wachtl) Infestation on Douglas Fir. Unpublished repore for Professor J. H. G. Smith, Faculty of Forestry, U.B.C.

McCRACKEN, and D. DANIEL. 1961. A Guide to FORTRAN Programming. John Wiley and Sons, New York.

SMITH J. H. G. and J. W. Ker. 1957. Some Distributions Encountered in Sampling Forest Stands. For. Sc. Vol. 3. No. 2 pp. 137-143.

STEEL, G. D. and J. H. TORRIE, 1960. Principles and Procedures of Statistics. McGraw-Hill Book Co. Inc. New York.

\section{TABle of Log Volume Factors}

By C. Joergensen ${ }^{1}$

The following factors represent volume, in cubic feet, per foot of log length; hence the volume of a log equals its length times the appropriate factor, as determined from the two end-diameters.

The volume factor for a given $\log$ is found in the row corresponding to smallest diameter (d) of the $\log$, and in the column corresponding to the difference (D-d) between largest diameter (D) and smallest diameter.

\section{EXAMPLE:}

$\begin{array}{lc}\text { largest diameter }(D) & 20 \text { inches } \\ \text { smallest diameter }(d) & 16 \text { inches } \\ \text { difference }(D-d) & 4 \text { inches } \\ \text { length }(L) & 32 \text { feet } \\ \text { factor }(\text { row } 16, \text { col. } 4) & 1.789 \\ \text { volume }(1.789 \times 32) & 57.248 \mathrm{cu} . \mathrm{ft} .\end{array}$

Attention is drawn to the term smallest diameter, which must be used as index to rows, regardless of whether it happens to be the top or the butt diameter. Normally, top diameter is smaller than butt diameter; but this may be reversed, for example, by a defect deduction at the butt end.

The formula used to calculate the volume factors $(v)$ is a transposed version of the Smalian formula (length $=1$ foot) :

$$
\mathrm{v}=\left(\mathrm{d}^{2}+\mathrm{D}^{2}\right) \times 0.00272707696
$$

Log volumes calculated by the factor method are identical with those obtained from the authorized Table of Ten Times Volume of Cylinders in Cubic Feet.

\footnotetext{
${ }^{1}$ Columbia Cellulose Company Limited, Vancouver, B.C.
} 